\title{
ON USING GUERRILLA IN BUSINESS-TO-BUSINESS COMMUNICATION: THE MANAGERS' VIEWS
}

\author{
Belem Barbosa, ${ }^{1}$ Dolores Silva, ${ }^{2}$ Claudia Amaral Santos, ${ }^{3}$ Sandra Filipe ${ }^{4}$
}

\begin{abstract}
Guerrilla marketing is an innovative approach to communicate with customers and to capture their attention essentially due to its inherent creativity, unconventional media, and low cost. Despite the interesting contributions in the literature on this topic, most of what is known about guerrilla marketing is confined to its use and impact on consumers. This study aims to fill a gap identified in the guerrilla marketing literature by conducting an exploratory research study on the propensity of performing guerrilla marketing campaigns in a Business-to-Business (B2B) context. The research objectives of this paper are (i) identifying the perceptions of B2B managers on guerrilla marketing campaigns and (ii) exploring determinants of the adoption of guerrilla marketing campaigns targeted at corporate customers.

We present the results of a qualitative research study comprising 12 semi-structured interviews with managers of different business areas. A content analysis was performed using Nvivo software.

Participants in this study demonstrated that B2B managers recognize and value the advantages associated with guerrilla communication, which is in many instances seen as useful and viable for the B2B sector. The propensity for adoption is dependent on internal factors such as corporate culture, managers' and collaborators' profiles, risk-proneness, market share, and product innovativeness, but also on the sector's usual practices of innovation and communication. Guerrilla marketing campaigns are more appropriate for attracting new B2B customers and need to be carefully adapted to the targets' profiles and preferences.
\end{abstract}

JEL Classification Numbers: M31; DOI: http://dx.doi.org/10.12955/cbup.v6.1126

Keywords: B2B communication, Guerrilla marketing, Guerrilla marketing campaigns, Unconventional communication

\section{Introduction}

Guerrilla marketing is a concept that has been capturing practitioners, consumers and media attention, not only due to its provocative and non-dogmatic characteristics but also because of its efficiency and the impacts its communication campaigns have attained. Literally, it is an unconventional marketing approach that develops high impact actions through creativity and unusual media and at a very low cost when compared to conventional advertising campaigns. The high return on investment is achieved with the collaboration of the target market, since the communication campaigns are directed toward a small group, relying on the creation of a big impact on those people and a consequent viral propagation. Thus, guerrilla communication is leveraged by word-of-mouth communication, including not only its online version but also specialized magazines to newspapers and TV news. Although the best-known cases of guerrilla marketing campaigns are predominantly directed to the consumer market, we consider this approach to be relevant and viable for Business-to-Business (B2B) companies to communicate with its target markets in a distinctive way. Thus, this paper aims to respond to a gap identified in the literature by exploring the intention to use guerrilla marketing campaigns in B2B sectors. The research objectives of this paper are (i) identifying the perceptions of B2B managers on guerrilla marketing campaigns and (ii) exploring determinants of the adoption of guerrilla marketing campaigns targeted at corporate customers. We present the main contributions of literature on guerrilla marketing that served as a basis to the preparation of the qualitative study conducted with the contribution of $12 \mathrm{~B} 2 \mathrm{~B}$ managers. The conclusions of this study provide relevant cues to $\mathrm{B} 2 \mathrm{~B}$ managers who intend to do guerrilla campaigns, and to guerrilla marketing agencies that want to offer solutions for the $\mathrm{B} 2 \mathrm{~B}$ sector.

\section{Literature review}

The concept of guerrilla marketing was first introduced by Jay Conrad Levinson in 1982 and was generically defined as the development of marketing activities in non-conventional media with very low budgets. Its success is based on the use of innovative and economically efficient marketing techniques (Levinson, 2007) directed at a specific market niche, and having a small crowd as a target (Isaac, 2014). Hutter and Hoffman (2011) defined guerrilla marketing as unconventional, low-cost publicity campaigns that have as a core purpose to attract the attention of target markets, causing

\footnotetext{
${ }^{1}$ GOVCOPP, University of Aveiro, belem.barbosa@ua.pt

${ }^{2}$ University of Aveiro, doloresdesousasilva@gmail.com

${ }^{3}$ GOVCOPP, University of Aveiro, claudia.amaral@ua.pt

${ }^{4}$ GOVCOPP, University of Aveiro, sandrafilipe@ua.pt
} 
surprise and prompting the audience to spontaneously collaborate with the campaign by spreading it through other consumers.

Guerrilla marketing comprises ambient marketing, sensation marketing, and viral marketing (Hutter and Hoffman 2011), as well as more recent techniques as branded flash mobs (Grant, 2016). These approaches are characterized by being different and innovative when compared to traditional marketing techniques and have as an objective to instigate surprise by non-anticipation and emotion. Guerrilla marketing aims to challenge the saturation of traditional marketing communication means, living side by side with consumers (Nufer, 2013) and implementing unexpected communication practices to attract its targets (Grant 2016). McNaughton (2008) argues that the main power of guerrilla communication lies in its public relations' role, overcoming traditional media saturation and fragmentation, and driving consumer interaction. From all guerrilla marketing characteristics, Levinson $(2007,2010)$ highlights creativity as the one which can reach that purpose, since it is creativity that attracts consumers and creates a greater impact, despite its low budget. Creativity may be visible for instance in the use of unconventional channels, which is particularly common in guerrilla marketing - with the premise that everything can be eligible as a means of publicity (Levinson, 2007).

As explained by Hutter and Hoffman (2014), in opposition to traditional marketing in which surprise appears normally confined to the message, guerrilla marketing includes unexpectedness also in the media, design and placement, being consequently more efficient. In fact, the surprise effect associated with the use of unconventional media makes marketing communication more visible and harder to ignore (Himpe, 2008). In addition, creativity and imagination turn campaigns into high impact tools, since although they interact with a reduced number of targets, they manage to call the attention of a high number of recipients through surprise and diffusion repercussions, obtaining their collaboration through word-of-mouth communication (Hutter \& Hoffmann, 2011). In a recent study, Dinh and Mai (2016) concluded that the creativity that results from combining novelty and relevance has a stronger effect on word-of-mouth intention. For that to happen it is essential to provide emotions to consumers, as when they feel strong emotions, they become more motivated to share their experiences (Hutter \& Hoffmann, 2011). In fact, guerrilla communication uses chock recurrently precisely to stand out from the crowd and create a strong emotional impact on its target market. Looking at the consumer side, Dahlén, Granlund and Grenros (2009) found that communication campaigns using non-traditional media go beyond getting attention, as they also enhance consumer perceived value of marketing, which in turn affects the intention to buy and to spread the word, thus being an effective means of reaching customers. Hutter and Hoffmann (2011) suggest that guerrilla marketing can be used as a tool to construct and enhance consumer relationship.

Therefore, although there is a risk in conducting unpredictable and unexpected campaigns, the advantages of using guerrilla approaches are strongly supported in the literature. However, and despite the lower cost and high return on investment associated to those campaigns, not all companies have the same propensity to use this type of strategy. Szabo, Hortovanyi, Tarody, Ferincz, and Dobak (2011) suggest that entrepreneurs and SME founders have a higher propensity to innovate and use creativity, new combinations of marketing tools, and unconventional marketing approaches as compared to conventional marketers. Consequently, they are more propense to use guerrilla communication strategies. Moreover, these authors stress that they are particularly interested in persuading potential customers to try out or buy the company's offers, which indicates probably an increased adequacy to target prospects as compared to a company's customers (Szabo et al., 2011).

One of the arguments in favour of choosing guerrilla marketing for a communication strategy is the recognized consumers' saturation and overexposure to traditional advertising (e.g., Dahlén et al., 2008; Hutter \& Hoffman, 2011, 2014; Nufer, 2013) and the consequent need for overcoming information overload and conquering the attention of the target market. Indeed, communication in the business market also shares this challenge of capturing the attention of existent and potential customers. For that reason, this paper argues that guerrilla marketing can offer interesting opportunities to B2B communication. 


\section{Data and methodology}

This study adopted the exploratory research model that best suited the purpose of understanding B2B managers' perceptions on guerrilla marketing in order to obtain information on their possible motivations and intentions when using this strategy. The qualitative research was based on semistructured interviews to business managers with corporate portfolios. A total of 12 interviews were conducted in October 2017, and the interviewees were managers with different demographics and professional profiles, and distinct working time periods and companies, as described in Table 1 . The number of interviewees was sufficient for data saturation to be reached. Interviews were recorded and further transcribed. Categories and topics were codified and analysed with Nvivo 11 software.

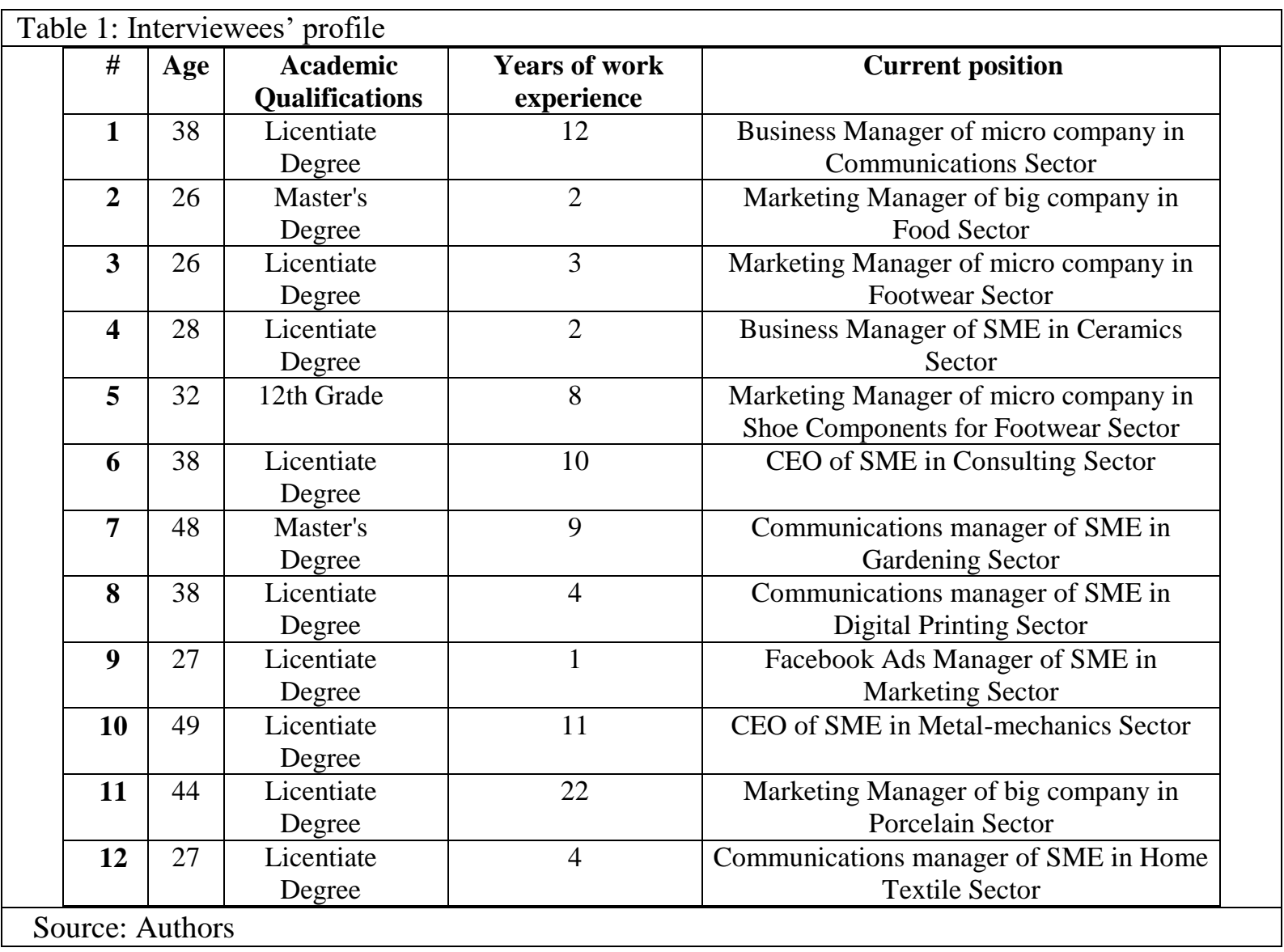

\section{Results and Discussion}

It became clear from the interviews that the B2B managers who participated in this study did not have a solid knowledge on the topic of guerrilla marketing. Although they were familiar with the concept and its advantages generically, participants recognized that they had never had any contact with similar campaigns, and few were able to define or spontaneously identify all the characteristics of guerrilla marketing strategies.

Nonetheless, managers were unanimous in recognizing the advantages of guerrilla marketing approaches and their relevancy, especially in B2B contexts. From all guerrilla marketing characteristics, creativity and the differentiation it conveys to communication were the ones most highlighted in B2B managers' insights. For instance, interviewee 5 stated: "I think that today in the sector I'm in, this is tremendously important. It is a differentiation factor, it truly is."

Another participant in the study pointed out that creativity in a B2B context might be more complex, not only regarding the need to combine rational and emotional communication, but also the need to compete for the attention of corporate customers who have less time and are less available to marketing communication. This is motivated by the fact that "B2B is extremely rational, so it is important to put an emotional component inside what is a rational need for information. As people have much less time and predisposition to deal with communication, it has to be extremely intelligent" (Interviewee 8). 
Low cost was one of guerrilla marketing characteristics most appreciated by B2B managers, and clearly one of its main advantages, as underlined by Interviewee 3, since many times communication budgets for B2B segments are considerably limited. Interviewee 7 revealed that in his company the communications budget is aimed primarily at the consumer market: "our (communications) campaign is focused on end consumers and absorbs the majority of the annual communications budget (...) Whereas everything we do in B2B is low-cost initiatives, and as we use a salesforce extensively, which is a cost that the company already has in order to sell, it is perfectly adaptable to B2B".

Similarly, the participants in this study shared their opinions on the appropriateness of several guerrilla communication strategies to the B2B market. The diffusion effect is especially attractive since it recognizes and asserts the exceptional value of word-of-mouth as more efficient, reliable and persuasive than any commercial messages. Several of the interviewees' narratives emphasized the importance of word-of-mouth communication in a B2B context for its decisive role in the development of companies' credibility. However, some of the participants argued that virality is considerably harder to obtain in B2B contexts, as compared to the more common processes with final consumers.

Concerning the surprise effect of guerrilla marketing, the opinion of B2B managers is that it can be interesting for a first approach and can result in high levels of engagement if the communication strategy is well structured. One of the interviewees stated that "the (surprise effect) is fit for a first approach because it is important to create an impact (...) to reach through this may cause a lasting effect." Thus, managers agreed on the opportunities generated by the surprise effect, in particular to attract the attention of new clients, underlining, however, the need for those approaches to be coherent with the company's marketing strategy, namely with its corporate culture. Interviewee 2 stressed that the surprise effect, if well sustained by creativity, can bring very good results to the company: "I associate (the surprise effect) to novelty because we are the first and that creates a good image, if it's well done ... everything that comes afterward seems almost like an imitation."

While all participants were unanimous in determining the advantages of guerrilla marketing, not all showed a propensity to adopt a guerrilla approach aimed at their B2B customers. Those who did, stated that the adoption would have to be accomplished with precaution: "We have to adapt (the campaign) to the effects that result best, knowing the customer and the sector, and of course always with the proper balance." (Interviewee 7) Still, others indicated that guerrilla marketing was not adequate to deal with their corporate customers. One of the reasons for this refusal applies especially to approaches that will shock the target market. As stated by Interviewee 9, "It has to be tentative, the impact. There has to be an impact, yes, but it cannot cause shock". Another opinion that emerges is that as long as those strategies are balanced, well-prepared and adequate, they can be applied: "Provided it's not too shocking, too extreme. If they are subtler, more directed and adjusted to B2B context." (Interviewee 4)

Indeed, risk perception associated with guerrilla marketing was evident, as exemplified by one of the participants: "campaigns have to be really well-structured, because they may not always reach positive results." (Interviewee 12) In this context, another interviewee advocated that the risk is worth taking and that companies should try to innovate and do different because the positive effects surpass the negative ones: "Sometimes we can also conclude that it's better to be talked about for a negative thing, than not to be talked about at all (...) people ended up looking for us, and this is a positive point that results from a negative point." (Interviewee 5)

In reality, some of the interviewees saw in guerrilla marketing the opportunity to be different, as explained by Interviewee 9: "All the characteristics we discussed make the company stand out, that is, they may have negative and positive impacts, but there's always a risk associated to it, even in traditional communication; however, I see big advantages in doing B2B guerrilla marketing, because for one thing it's not much used in Portugal and that differentiation fact alone can help a lot in the company's positioning."

\section{Facilitators and inhibitors of guerrilla marketing adoption by B2B managers}

From the previous remarks it became evident that despite the obvious advantages perceived in the adoption of guerrilla marketing to communicate with customers, the managers that participated in this study highlighted that the transfer process to B2B market is not straightforward and several factors 
may facilitate or inhibit its adoption. Cultural issues were the first to be mentioned, with managers suggesting that the national and international context within which the company performs influence the appropriateness of a guerrilla marketing campaign, as illustrated by one of the interviewees: "Guerrilla marketing in Portugal still has a lot to grow, starting with the definition, because our market is very different; if we look at Brazil they don't do anything else but guerrilla marketing; it's different, it's their culture, it's a matter of education." (Interviewee 1)

Another determinant factor for the feasibility of guerrilla marketing adoption is the working sector itself. In more traditional sectors where rational and formal communication dominates, the use of guerrilla marketing actions is seen as more risky, inefficient and even inappropriate, especially when communication is dominantly rational. Indeed, several interviewees stated that it might succeed in other areas of B2B different from theirs, as it was the case of Interviewee 10: "The surprise effect may be catastrophic. It's too informal for our area. (...) (Guerrilla marketing) is a beautiful thing, really. But it wouldn't bring any return or impact because [our product is] very serious and safe, with lots of certifications, people would almost be tempted to play with that, from my point of view."

In the opposite direction, other participants indicated that their business areas are particularly propense to apply guerrilla marketing in a B2B context, namely to differentiate themselves from the competition and to be in consonance with the dominant creativity of the sector. The digital sector was one example: "Being a digital company, mentalities are much more open to this kind of approach, it's not a traditional B2B mindset" (Interviewee 9). Other example came from the innovative sector of fashion: "I think it's adequate. Mentalities allow that. More and more people look at innovation and we are in the fashion area, fashion is associated with extravagance, and defiance. So I believe it would be fruitful to plan a strategy in that way." (Interviewee 5) However, even in business sectors best known for innovative and creative products, one interviewee argued that those strategies should not prevail over others, i.e. when the product is really creative, communication should not overshadow it and let the product communicate by itself, as referred by interviewee 11: "Creativity in the sector where we work is vital in product development, but not in product presentation, nor in product commercialization."

In a similar way, the appropriateness of guerrilla marketing strategies is necessarily dependent on the corporate culture and on the profile of managers and collaborators. Interviewee 2 exemplified: "The way people think, in the case of the top managers themselves... if we have a board a little bit older, these tools are not welcome." Identical issues also apply to customers: "it depends always on the level of maturity of organizations, who is on each side, if [the] organization is already experienced in guerrilla marketing" (Interviewee 10).

The idea was also discussed that not being a market leader makes the use of alternative approaches more attractive (and eventually riskier): "We are not market leaders, but the team is young, we always try (...) and we believe that with the evolution of the market it will be easier. Generations will renovate themselves and it's easier for the younger ones to accept different things." (Interviewee 7)

\section{Discussion}

Following Nufer (2013) and Grant (2016), guerrilla marketing can be considered by B2B managers a valid strategy to challenge the saturation of traditional campaigns, causing greater impact on an audience that does not expect to be treated outside its corporate format. In fact, Levinson (2007) suggests that the inclusion of the guerrilla marketing concept intends particularly to disrupt the way companies manage their businesses so as to maximize the promotion of its resources, thus being a beneficial strategy for B2B managers. Nonetheless, several factors make this adoption difficult. First, the need to enhance managers' familiarity with guerrilla marketing communications. More extensive dissemination and diffusion are needed, together with an assessment of perceived risk and appropriateness appraisal for each sector. Another important role will be performed by the adoption of inhibitors and facilitators, derived not only from the company's internal matrix but also from the sector where it stands and the profile of its customers. Among the internal factors, data collected emphasized the influence of corporate culture, the profile of managers and collaborators, a company's degree of innovation, market share and risk proneness. Factors related to the working sector indicate sectoral culture, innovation degree and recurrent communications' strategies. Lastly, data suggest more 
propensity to apply guerrilla marketing to attract new customers, although dependent on the profile of managers and collaborators.

\section{Conclusion}

This exploratory research demonstrates the existence of interesting opportunities for guerrilla marketing in the B2B sector, but also the need for a more extensive dissemination and in-depth knowledge of guerrilla marketing techniques among companies. The adoption of guerrilla marketing in the B2B context is applicable and may be an innovative way to promote and strengthen relations with corporate customers by asserting and emphasizing the characteristics that best fit each sector.

A final remark on the main limitations of this study. Although the number of interviews was adequate to the research methodology and objectives, and data saturation was achieved, results should not be generalized. Despite the relevance and interest of the topic, as demonstrated throughout the study, further analysis on the adoption on guerrilla marketing in B2B communication should be accomplished. In future research on this topic, it would be interesting to compare distinctions on perception and intention to use of guerrilla marketing approaches by B2B managers of different market sectors, and test if the adoption depends on factors such as managers' profile, company's dimension or marketing budget. It will also be essential to analyse corporate customers' perspective, namely by exploring the impact of guerrilla campaigns in the decision-making process, suppliers' selection and the development of long-term relationships among companies.

\section{Acknowledgements}

This work was financially supported by the research unit on Governance, Competitiveness and Public Policy (project POCI-01-0145-FEDER-006939), funded by FEDER funds through COMPETE2020 Programa Operacional Competitividade e Internacionalização (POCI) - and by national funds through FCT - Fundação para a Ciência e a Tecnologia.

\section{References}

Bruhn, M., Schnebelen, S., \& Schäfer, D. (2014). Industrial Marketing Management Antecedents and consequences of the quality of e-customer-to-customer interactions in B2B brand communities. Industrial Marketing Management, 43(1), 164176. doi:10.1016/j.indmarman.2013.08.008

Dahlén, M., Granlund, A., \& Grenros, M. (2009). The consumer-perceived value of non-traditional media: effects of brand reputation, appropriateness and expense. Journal of Consumer Marketing, 26(3), 155-163.

Dinh, T. D., \& Mai, K. N. (2016). Guerrilla marketing's effects on Gen Y's word-of-mouth intention-a mediation of credibility. Asia Pacific Journal of Marketing and Logistics, 28(1), 4-22.

Grant, P. S. (2016). Understanding branded flash mobs: The nature of the concept, stakeholder motivations, and avenues for future research. Journal of Marketing Communications, 22(4), 349-366.

Himpe, T. (2008). Advertising is dead: Long live advertising. London: Thames and Hudson.

Hutter, K., \& Hoffmann, S. (2011). Guerrilla marketing: The nature of the concept and propositions for further research. Asian Journal of Marketing, 5(2), 39-54.

Hutter, K., \& Hoffmann, S. (2014). Surprise, surprise. Ambient media as a promotion tool for retailers. Journal of Retailing, 90(1), 93-110.

Isaac, A. A. (2014). Analysis of Guerrilla and Traditional Marketing Interface in Improving the Productivity of Organizational Marketing in Small and Medium Size Enterprises (SMEs) in Nigeria. Journal of Small Business and Entrepreneurship Development, 2(1), 175-190.

Levinson, J. C. \& Gibson, S. (2010). Guerrilla Social Media Marketing. Irvine: Entrepreneur Press.

Levinson, J. C. (2007). Guerrilla Marketing Attack (4th ed.). Boston: Houghton Mifflin Company.

McNaughton, M. J. (2008). Guerrilla communication, visual consumption, and consumer public relations. Public Relations Review, 34(3), 303-305.

Nufer, G. (2013). Guerrilla Marketing — Innovative or Parasitic Marketing ? Modern Economy, 4, 1-6.

Szabo, R. Z., Hortovanyi, L., Tarody, D. F., Ferincz, A., \& Dobak, M. (2011). The role of knowledge in entrepreneurial marketing. International Journal of Entrepreneurial Venturing, 3(2), 149-167. 